\title{
Synthesis and characterization of novel polyvalent organoiodine compounds
}

\author{
Bindu V. Meprathu ${ }^{\ddagger}$ and John D. Protasiewicz ${ }^{\dagger *}$ \\ ${ }^{\dagger}$ Department of Chemistry, Case Western Reserve University Cleveland, Ohio 44106-7078 \\ ${ }^{\ddagger}$ Cancer Center, Case Western Reserve University, Cleveland, Ohio 44106-5065 \\ E-mail: jdp5@po.cwru.edu
}

Dedicated to Professor Anastasios Varvoglis

(received 1 Feb 03; accepted 16 Feb 03; published on the web 04 May 03)

\begin{abstract}
Synthesis and characterization of soluble analogues of iodosylbenzene PhIO and (tosyliminoiodo)benzene PhINTs are reported. The syntheses of 4-trifluoromethyl-2-(tertbutylsulfonyl)iodosylbenzene (3) and 4-trifluoromethyl-2-(tert-butylsulfonyl)(tosylimino)iodobenzene (4) increase the repertoire of available soluble organoiodine(III) based oxo- and nitrene precursors. We also report the synthesis of a new organoiodine(V) compound, 4-trifluoromethyl-2-(tert-butylsulfonyl)iodylbenzene.
\end{abstract}

Keywords: Polyvalent organoiodine compounds, PhINTs, PhIO, secondary bonding

\section{Introduction}

Polyvalent organoiodine compounds have found wide synthetic applications in many organic transformations. ${ }^{1}$ In particular, tosyliminoiodobenzene (PhINTs) and iodosylbenzene (PhIO) have found favor as primary oxidants in metal-catalyzed aziridinations and epoxidations of various olefins. ${ }^{2}$ However, the insoluble nature of these reagents, and hence the heterogeneous conditions involving them, hinder efforts to ascertain the reaction mechanism and improve efficiency. The insoluble nature of organoiodine(III) compounds of type $\operatorname{ArIX}_{2}$ (where $\mathrm{X}=\mathrm{NTs}$, $\mathrm{O}$ or $\mathrm{Cl}_{2}$ ) stems in large part from polymeric networks of $\mathrm{I} \cdot \mathrm{X}$ secondary bonding in the solid state. ${ }^{3}$ Recent efforts in our group have been focussed on the solubilization of these important compounds by the modification of secondary bonding interactions. ${ }^{4}$

The characteristic I·O secondary bonding in polyvalent iodine compounds have been utilized to direct self-assembly of organoiodine(III) molecules into chiral and optically pure hypervalent iodine macromolecules and to promote asymmetric oxytosylation reactions. ${ }^{5}$ During the course of our study of secondary bonding interactions in organoiodine(III) compounds, soluble 
analogues of $\mathrm{PhIO}$ and PhINTs were realized in the synthesis of iodosylarene $\mathbf{1}$ and (tosyliminoiodo)arene 2 , by placing an appropriate substituent in the ortho position of the phenyl ring. ${ }^{6}$

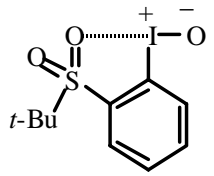

1

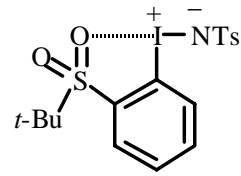

2

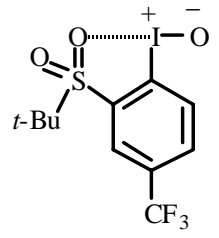

3

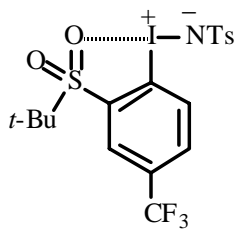

4

\section{Figure 1}

Isolation of primary nitrene sources such as 2 and other $\mathrm{ArINSO}_{2} \mathrm{Ar}$ ' typically require the electron withdrawing and stabilizing effects of a sulfonyl group. Compound $\mathbf{2}$ is thus closely related to the well known related carbene source phenyliodonium bis(phenylsulfonyl)methylide $\mathrm{PhI}=\mathrm{C}\left(\mathrm{SO}_{2} \mathrm{Ph}\right)_{2}$ first reported by Varvoglis and coworkers. ${ }^{7}$ Compounds $\mathbf{1}$ and $\mathbf{2}$ were found to be effective in metal catalyzed oxidations; however, the epoxidation reactions involving iodosylarene $\mathbf{1}$ were plagued by the competing disproportionation of $\mathbf{1}$ to the corresponding iodoarene (I(I)) and iodylarene (I(V)) (equation 1). Iodosylbenzene has been reported to undergo ready disproportionation catalyzed by metal porphyrin or upon heating. ${ }^{8}$ The outcome of metal catalyzed epoxidation reactions might be improved by stabilizing soluble iodosylarene $\mathbf{1}$ toward disproportionation.

$$
2 \mathrm{ArlO} \longrightarrow \mathrm{Arl}+\mathrm{ArlO}_{2}
$$

Electron-withdrawing substituents on the ring have been reported to enhance the stability of organoiodine(III) compounds such as $\mathrm{ArICl}_{2}$, in solution. For instance, a solution of $\mathrm{PhICl}_{2}$ in $\mathrm{CCl}_{4}$ loses its oxidizing power at the rate of $0.5 \%$ per day at $20{ }^{\circ} \mathrm{C}$. Under similar conditions, $p$ $\mathrm{FC}_{6} \mathrm{H}_{4} \mathrm{ICl}_{2}$ is reduced only at the rate of $0.04 \%$ per day. ${ }^{9}$ Derivatives of polyvalent iodine compounds with an alkyl substituent at iodine, such as perfluoroalkyliodosyl derivatives, have shown significant stabilization upon introduction of an electron-withdrawing substituent in the alkyl moiety. ${ }^{10}$ It can be reasoned that reducing the electron density around the iodine atom can stabilize iodosylarene $\mathbf{1}$ and reduce its tendency towards disproportionation. With the aim of further stabilization of soluble organoiodine(III) species, iodosylarene $\mathbf{3}$ and (tosyliminoiodo)arene 4, possessing the electron withdrawing trifluoromethyl group were prepared and characterized.

\section{Results and Discussion}


Iodanes $\mathbf{3}$ and $\mathbf{4}$ were obtained in moderate to good yields by following the synthetic steps outlined in Scheme 1. The unsymmetrically substituted thioether $\mathbf{5}$ was synthesized from commercially available 3-(trifluoromethyl)bromobenzene by metal-halogen exchange using $t$ BuLi followed by reaction of $t$-butyl disulfide Compound 5 was readily oxidized to sulfone $\mathbf{6}$ in good yield. ${ }^{11}$ The Snieckus method for directed ortho-lithiation of sulfones was adapted for the synthesis of iodoarene $7 .^{12}$ Two geometric isomers of this iodoarene (7a and $7 \mathbf{b}$ in a $4: 1$ ratio) were obtained, and the desired 7a was isolated by recrystallization of the mixture of isomers from diethyl ether.

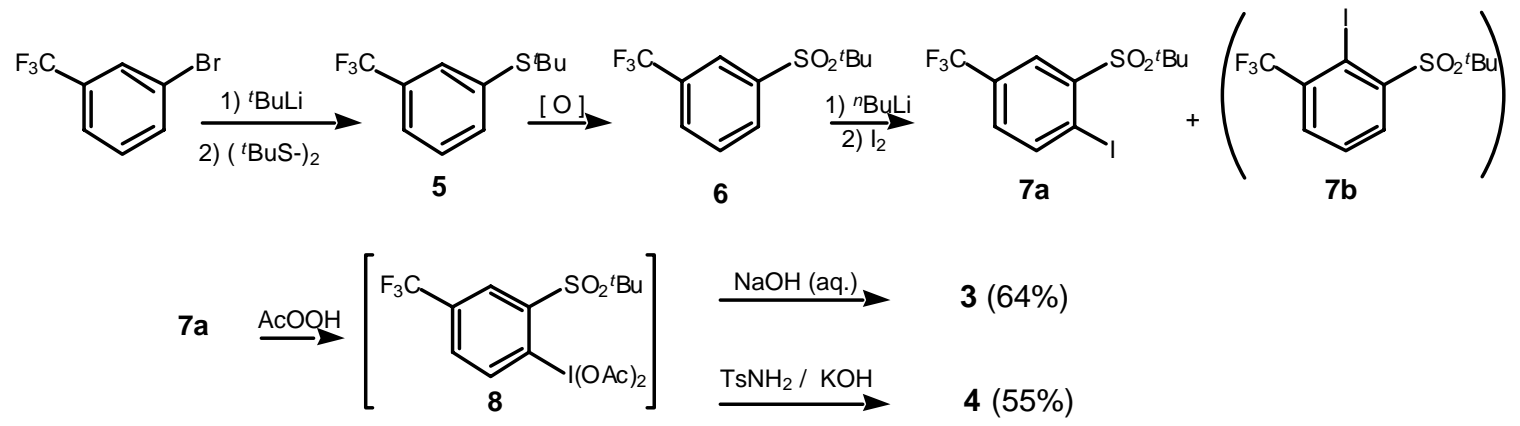

\section{Scheme 1}

Diacetoxyiodoarene 8 obtained by the action of peracetic acid on 7a was used as such, without purification, to synthesize the yellow iodosylarene $\mathbf{3}$ and pale yellow (tosyliminoiodo)arene $\mathbf{4}$ in moderate yields (55-65\%). Iodanes $\mathbf{3}$ and $\mathbf{4}$ were characterized by spectroscopic data and elemental analysis. Like the parent soluble iodanes $\mathbf{1}$ and $\mathbf{2}$, these novel iodanes were also found to be soluble in organic media. A $0.30 \mathrm{M}$ solution of iodosylarene 3 (which is a $\sim$-fold increase over the solubility of 1), and a $0.05 \mathrm{M}$ solution of tosyliminoiodoarene $\mathbf{4}$ could be prepared in chloroform.

Iodosylarene 3 was evaluated to be only slightly more stable to disproportionation, however, with respect to iodosylarene 1 (69\% of 3 in $\mathrm{CDCl}_{3}$ underwent disproportionation compared to $81 \%$ of 1 within the same period of time). The product of this diproportionation, 4trifluoromethyl-2-(tert-butylsulfonyl)iodylbenzene (9), was independently synthesized as a white solid by the oxidation of 7a with aqueous sodium hypochlorate (commercial bleach). Compound 9 was characterized by ${ }^{1} \mathrm{H}$ NMR data and elemental analysis. Consistent with its precipitation during disproprortionation of $\mathbf{3}$, iodylarene $\mathbf{9}$ was found to be insoluble in most organic solvents, except DMSO, which was used to record its solution NMR spectrum.

Preliminary investigations on the reactivity of $\mathbf{3}$ and $\mathbf{4}$ indicated these novel iodanes to be competent oxidants. For example, styrene oxide was obtained in $15 \%$ yield upon epoxidation using 3 under $\mathrm{Mn}$ (Salen)Cl catalysis. The relatively low yields are indicative of the competitive catalytic disproportionation of iodosylarene 3 by the manganese catalyst (Scheme 2). Consistent with this proposal, mixtures of $\mathbf{9}$, styrene, and the manganese catalyst produced no epoxide. 
However, iodylarene 9 does quantitatively oxidize methyl phenyl sulfide to methyl phenyl sulfoxide.

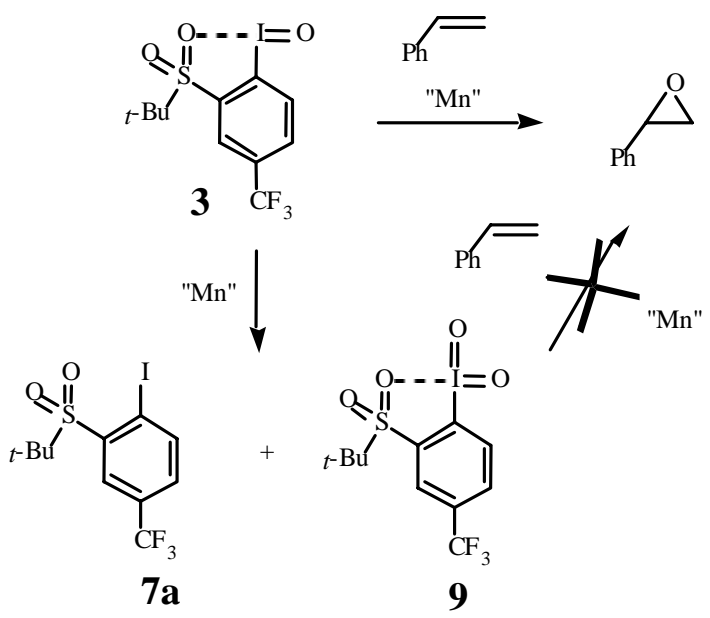

\section{Scheme 2}

\section{Conclusions}

In summary, the synthesis and characterization of further soluble analogues of PhINTs and PhIO are reported. The new iodanes contain an electron-withdrawing substitute in iodoarene residue and were assessed to be moderately effective oxidants, but the iodosyl derivative still underwent rather facile disproportionation. Introduction of even stronger electron-withdrawing moiety in the design of these organoiodine(III) compounds might have a greater impact upon the stability of iodosylarenes for use as primary oxo- and nitrene precursors in catalytic atom and group transfer. 


\section{Experimental Section}

General Procedures. Alkyllithium reagents were purchased from Aldrich and titrated with diphenylacetic acid prior to use. Reactions involving the manipulation of air and water sensitive reagents were performed under a nitrogen atmosphere using Schlenk techniques. THF was distilled from sodium benzophenone ketyl. $\mathrm{CH}_{2} \mathrm{Cl}_{2}$ and $\mathrm{CH}_{3} \mathrm{CN}$ were distilled from calcium hydride. ${ }^{1} \mathrm{H}$ and ${ }^{13} \mathrm{C}\left\{{ }^{1} \mathrm{H}\right\}$ NMR spectra were recorded on Varian XL200 or Varian XL 300 spectrometers. ${ }^{19} \mathrm{~F}\left\{{ }^{1} \mathrm{H}\right\}$ NMR spectra were recorded on Varian XL 300 spectrometer. Chemical shifts were referenced internally to residual solvent signals $\left({ }^{1} \mathrm{H}\right)$ or externally by using TFA $\left({ }^{19} \mathrm{~F}\right)$. HR-MS spectra were recorded on a Carlo-Erba Mass Spectrometer. GC-MS spectra were recorded on a HP5890 Series II Gas Chromatograph equipped with a HP 5972 Mass Selective Detector. Elemental analyses were performed by Qualitative Technologies Inc.(QTI), Whitehouse, NJ.

3-(Trifluoromethylphenyl) tert-butyl thioether (5). To a magnetically stirred solution of 3(trifluoromethyl)bromobenzene $(11.3 \mathrm{~g}, 50.0 \mathrm{mmol})$ in THF $(200 \mathrm{~mL})$, cooled to $-42{ }^{\circ} \mathrm{C}$, was added $t$-BuLi (46 mL of 1.2M soln in pentane, $55 \mathrm{mmol}$ ) dropwise over a period of 40 minutes. The resulting reddish brown solution was stirred for 40 minutes and tert-butyl disulfide (8.9 g, $50 \mathrm{mmol}$ ) added into the reaction flask dropwise via syringe with constant stirring. The reaction mixture was slowly allowed to reach room temperature and water (50 mL) added to the flask to yield two homogeneous phases. The organic phase was separated and the aqueous phase extracted with diethyl ether ( 3 x $25 \mathrm{~mL}$ ). The combined organic extracts were washed with brine and dried over $\mathrm{MgSO}_{4}$. The solvents were removed in vacuo to obtain a brown viscous liquid. The crude liquid was distilled to obtain a colorless liquid and identified by GC-MS analysis to be 5. Yield: 5.26 g (45\%). ${ }^{1} \mathrm{H} \mathrm{NMR}\left(\mathrm{CDCl}_{3}, 200 \mathrm{MHz}\right): \delta 7.80(\mathrm{~s}, 1 \mathrm{H}), 7.72\left(\mathrm{~d}, 1 \mathrm{H},{ }^{2} \mathrm{~J}_{\mathrm{HH}}=7.7\right.$ $\mathrm{Hz}$ ), 7.62 (d, $\left.1 \mathrm{H},{ }^{2} \mathrm{~J}_{\mathrm{HH}}=7.7 \mathrm{~Hz}\right), 7.46\left(\mathrm{t}, 1 \mathrm{H},{ }^{2} \mathrm{~J}_{\mathrm{HH}}=7.7 \mathrm{~Hz}\right), 1.30$ (s, $\left.9 \mathrm{H}\right)$.

3-(Trifluoromethylphenyl) tert-butyl sulfone (6). To thioether $6.5 \mathrm{~g}$ of 5 (28 mmol) was added $30 \% \mathrm{H}_{2} \mathrm{O}_{2}(20 \mathrm{~mL})$ and glacial acetic acid $(20 \mathrm{~mL})$, and the mixture stirred at $85{ }^{\circ} \mathrm{C}$ for $4 \mathrm{~h}$ to obtain a white precipitate. This solid was isolated by filtration and washed with water until the washings showed no trace of acid by $\mathrm{pH}$ paper. The solid was recrystallised from $\mathrm{MeOH}$, and dried in vacuo to obtain 6 as a colorless crystalline solid. Yield: $6.10 \mathrm{~g}(82 \%) . \mathrm{Mp}=63{ }^{\circ} \mathrm{C} .{ }^{1} \mathrm{H}$ NMR (CDCl $3,200 \mathrm{MHz}$ ): $\delta 8.15$ (s, $1 \mathrm{H}), 8.09$ (d, $1 \mathrm{H}, \mathrm{J}=7.8 \mathrm{~Hz}), 7.72$ (t, $1 \mathrm{H}, \mathrm{J}=7.8 \mathrm{~Hz}$ ), 7.92 (d, $1 \mathrm{H}, \mathrm{J}=7.78 \mathrm{~Hz}), 1.36$ (s, $9 \mathrm{H}) .{ }^{19} \mathrm{~F} \mathrm{NMR}\left(\mathrm{CDCl}_{3}, 282.2 \mathrm{MHz}\right) \delta: 32.4$. Anal. Calcd for $\mathrm{C}_{11} \mathrm{H}_{13} \mathrm{O}_{2} \mathrm{SF}_{3}$ : C, 49.62; H, 4.92. Found: C, 49.46; H, 4.76.

4-Trifluoromethyl-2-(tert-butylsulfonyl)iodobenzene (7a). To a magnetically stirred solution of 6 (0.50 g, $2.3 \mathrm{mmol})$ in THF $(20 \mathrm{~mL})$ cooled to $-78{ }^{\circ} \mathrm{C}$ was added $0.98 \mathrm{~mL}$ of $n$-BuLi $(2.56 \mathrm{M}$ solution in hexanes, $2.5 \mathrm{mmol})$ ) dropwise, to obtain a dark red solution. The reaction mixture was stirred for 20 minutes, and a solution of iodine $(0.70 \mathrm{~g}, 2.7 \mathrm{mmol})$ in THF (20 mL) added via cannula. After allowing the reaction mixture to warm to room temperature, aqueous $\mathrm{Na}_{2} \mathrm{SO}_{3}$ was added to quench excess elemental iodine. The organic layer was separated and the aqueous layer 
extracted with diethyl ether ( $3 \times 25 \mathrm{~mL}$ ). The combined organic extracts were washed with brine and dried over $\mathrm{MgSO}_{4}$. The solvents were removed in vacuo to obtain a viscous oil. This material was recrystallized from diethyl ether to obtain 7a. Yield: $0.52 \mathrm{~g}(58 \%) .{ }^{1} \mathrm{H}$ NMR $\left(\mathrm{CDCl}_{3}, 300 \mathrm{MHz}\right.$ ): $\delta 8.32$ (a doublet and singlet are superimposed, $2 \mathrm{H},{ }^{2} \mathrm{~J}=8.5 \mathrm{~Hz}$ ), 7.46 (dd, $\left.1 \mathrm{H},{ }^{2} \mathrm{~J}=8.2 \mathrm{~Hz},{ }^{4} \mathrm{~J}=1.6 \mathrm{~Hz}\right), 1.43(\mathrm{~s}, 9 \mathrm{H}) .{ }^{19} \mathrm{~F} \mathrm{NMR}\left(\mathrm{CDCl}_{3}, 282.2 \mathrm{MHz}\right): \delta 32.1(\mathrm{~s}) .{ }^{13} \mathrm{C}\{\mathrm{H}\}$ NMR ( $\left.\mathrm{CDCl}_{3}, 75.5 \mathrm{MHz}\right): \delta$ 24.2, 63.0, $99.3\left(\mathrm{q},{ }^{3} \mathrm{~J}_{\mathrm{HF}}=19.8 \mathrm{~Hz}\right), 130.9\left(\mathrm{q},{ }^{1} \mathrm{~J}_{\mathrm{HF}}=22.8 \mathrm{~Hz}\right)$, 139.2, 144.8. HR-MS (EI, $\mathrm{C}_{11} \mathrm{H}_{12} \mathrm{O}_{2} \mathrm{~F}_{3} \mathrm{IS}$ ) Calcd: 391.9554. Found: 391.9552. Pertinent NMR signals assigned to $\mathbf{7 b}$ (as deduced from spectra of mixtures of $\mathbf{7 a}$ and $\mathbf{7 b}$. No attempt was made to isolate or purify $7 \mathbf{b}):{ }^{1} \mathrm{H} N \mathrm{NR}\left(\mathrm{CDCl}_{3}, 300 \mathrm{MHz}\right) \delta 7.87\left(\mathrm{~d}, 1 \mathrm{H},{ }^{2} \mathrm{~J}=6.6 \mathrm{~Hz}\right), 7.46$ (multiplet, $1 \mathrm{H}), 1.44$ (s, $9 \mathrm{H}$ ). (signal due to the third proton on the ring in $7 \mathbf{b}$ could not be distinguished due to overlap with signals from aromatic protons of 7a). ${ }^{19} \mathrm{~F} \mathrm{NMR}\left(\mathrm{CDCl}_{3}, 282.2 \mathrm{MHz}\right): \delta 34.4$ (s).

4-Trifluoromethyl-2-(tert-butylsulfonyl)iodosylbenzene (3). Acetic anhydride (2.4 mL) and $30 \% \mathrm{H}_{2} \mathrm{O}_{2}(0.6 \mathrm{~mL})$ was stirred at $42{ }^{\circ} \mathrm{C}$ for $5 \mathrm{~h}$. Iodoarene $7 \mathbf{a}(0.78 \mathrm{~g}, 2.0 \mathrm{mmol})$ was added to the resulting solution and the reaction mixture stirred at $30{ }^{\circ} \mathrm{C}$ for $24 \mathrm{~h}$ to result in a pale yellow solution. The progress of the reaction was monitored by TLC (benzene/silica gel plate) to ensure complete oxidation of 7a. The solvents were removed in vacuo, and the white solid obtained was treated with aqueous $3 \mathrm{~N} \mathrm{NaOH}(10 \mathrm{~mL})$ at $0{ }^{\circ} \mathrm{C}$, to obtain a yellow precipitate. The reaction mixture was stirred at $0{ }^{\circ} \mathrm{C}$ for $1 \mathrm{~h}$ and at room temperature for $1 \mathrm{~h}$. The yellow solid was isolated by filtration, washed with water and diethyl ether to obtain 3. Yield: $0.52 \mathrm{~g}(64 \%) .{ }^{1} \mathrm{H}$ NMR $\left(\mathrm{CDCl}_{3}, 300 \mathrm{MHz}\right.$ ): $\delta 8.32\left(\mathrm{~d}, 1 \mathrm{H},{ }^{2} \mathrm{~J}=8.4 \mathrm{~Hz}\right.$ ), 8.05 (a singlet and a doublet superimposed, ${ }^{2} \mathrm{~J}=$ $5.7 \mathrm{~Hz}), 1.43$ (s, $9 \mathrm{H}) .{ }^{19} \mathrm{~F} \mathrm{NMR}\left(\mathrm{CDCl}_{3}, 282.2 \mathrm{MHz}\right.$ ): $\delta 32.6$ (s). Anal. Calcd for $\mathrm{C}_{11} \mathrm{H}_{12} \mathrm{O}_{3} \mathrm{SF}_{3} \mathrm{I}$ : C, 32.37; H, 2.96. Found: C, 32.31; H, 2.80.

Solubility: $0.67 \mathrm{~mL}$ of $\mathrm{CDCl}_{3}$ was required to completely dissolve $83.3 \mathrm{mg}$ of 3 (ca $0.3 \mathrm{M}$ )

4-Trifluoromethyl-2-(tert-butylsulfonyl)-(tosylimino)iodobenzene (4). Acetic anhydride (1.2 $\mathrm{mL})$ and $30 \% \mathrm{H}_{2} \mathrm{O}_{2}(0.3 \mathrm{~mL})$ were stirred at $42{ }^{\circ} \mathrm{C}$ for $5 \mathrm{~h}$. Iodoarene $7 \mathrm{a}(0.40 \mathrm{~g}, 1.0 \mathrm{mmol})$ was added to the resulting solution and the reaction mixture stirred at $30{ }^{\circ} \mathrm{C}$ for $24 \mathrm{~h}$ to afford a pale yellow solution. The progress of the reaction was monitored by TLC (benzene/silica gel plate) to ensure complete oxidation of $\mathbf{7 a}$. The solvents were removed in vacuo, and the white solid obtained was treated with an ice-chilled solution of $\mathrm{KOH}(0.20 \mathrm{~g}, 3.5 \mathrm{mmol})$ and paratoluenesulfonamide $(0.17 \mathrm{~g}, 1.0 \mathrm{mmol})$ in methanol $(5 \mathrm{~mL})$. The resulting pale yellow solution was stirred for $1 \mathrm{~h}$ at $0{ }^{\circ} \mathrm{C}$ and for $1 \mathrm{~h}$ at room temperature. Crushed ice was added to the reaction mixture to obtain a yellow precipitate. This solid was isolated by filtration, washed with water and diethyl ether and dried in vacuo to obtain 4. Yield: $0.30 \mathrm{~g}(55 \%) .{ }^{1} \mathrm{H}$ NMR $\left(\mathrm{CDCl}_{3}, 300\right.$ MHz): $\delta 8.49$ (d, $\left.1 \mathrm{H},{ }^{2} \mathrm{~J}=8.5 \mathrm{~Hz}\right), 8.10(\mathrm{~s}, 1 \mathrm{H}), 8.03\left(\mathrm{dd}, 1 \mathrm{H},{ }^{2} \mathrm{~J}=8.3 \mathrm{~Hz},{ }^{4} \mathrm{~J}=1.7 \mathrm{~Hz}\right), 7.81(\mathrm{~d}$, $\left.2 \mathrm{H},{ }^{2} \mathrm{~J}=8.3 \mathrm{~Hz}\right), 7.24\left(\mathrm{~d}, 2 \mathrm{H},{ }^{2} \mathrm{~J}=7.9 \mathrm{~Hz}\right) .{ }^{19} \mathrm{~F} \mathrm{NMR}\left(\mathrm{CDCl}_{3}, 282.2 \mathrm{MHz}\right): \delta 32.4(\mathrm{~s})$. Anal. Calcd for $\mathrm{C}_{18} \mathrm{H}_{19} \mathrm{O}_{4} \mathrm{~S}_{2} \mathrm{~F}_{3} \mathrm{IN}$ 0.5 $\mathrm{H}_{2} \mathrm{O}$ : C. 37.90; H, 3.52; N, 2.45. Found: C, 37.77; H, 3.29; N 2.25. Solubility: $0.75 \mathrm{~mL}$ of $\mathrm{CDCl}_{3}$ was required to completely dissolve $21.2 \mathrm{mg}$ of 4 . (ca $0.05 \mathrm{M}$ ) 
4-Trifluoromethyl-2-(tert-butylsulfonyl)iodylbenzene (9). A mixture containing 6:4 ratio of 7a and $7 \mathbf{b}(\sim 1 \mathrm{~g})$ was dissolved in glacial acetic acid $(4 \mathrm{~mL})$ and mixed with commercial bleach (5.25\% aqueous $\mathrm{NaOCl}, 20 \mathrm{~mL})$. A white precipitate was observed immediately along with a sticky yellow paste. The mixture was stirred at room temperature for $16 \mathrm{~h}$ followed by the addition of water $(50 \mathrm{~mL})$. The white solid was isolated by filtration, washed with diethyl ether and dried to obtain the target iodylarene. Yield: $0.43 \mathrm{~g}(66 \%)$ based on a 6:4 ratio of 7a:7b. M.p $=162{ }^{\circ} \mathrm{C}$ (detonates). ${ }^{1} \mathrm{H}$ NMR (DMSO-d6, $300 \mathrm{MHz}$ ): $\delta 8.67\left(\mathrm{~d}, 1 \mathrm{H},{ }^{2} \mathrm{~J}=8.0 \mathrm{~Hz}\right.$ ), $8.53(\mathrm{~d}, 1 \mathrm{H}$, ${ }^{2} \mathrm{~J}=8.0 \mathrm{~Hz}$ ), $8.10(\mathrm{~s}, 1 \mathrm{H}), 1.35(\mathrm{~s}, 9 \mathrm{H})$. Anal. Calcd for $\mathrm{C}_{11} \mathrm{H}_{12} \mathrm{O}_{4} \mathrm{SF}_{3} \mathrm{I} \cdot 0.5 \mathrm{H}_{2} \mathrm{O}: \mathrm{C}, 30.50 ; \mathrm{H}$, 3.02. Found: C, 30.59; H, 2.76.

Epoxidation using 4-trifluoromethyl-2-(tert-butylsulfonyl)iodosylbenzene (3). To a suspension of styrene $(0.32 \mathrm{~mL}, 2.8 \mathrm{mmol})$ and (1R, 2R)-(-)-[1, 2-cyclohexanediamino-N, N'-bis(3, 5-di-tbutylsalicylidene)]manganese(III) chloride (8.9 mg, $14 \mu \mathrm{mol}$ ) in $\mathrm{CH}_{2} \mathrm{Cl}_{2}(5 \mathrm{~mL})$ was added 3 ( $0.10 \mathrm{~g}, 0.25 \mathrm{mmol})$, and the resulting dark brown solution stirred at room temperature for $1 \mathrm{~h}$ until all of 3 was consumed. Hexane $(10 \mathrm{~mL})$ was added and the resulting mixture passed through a short column of silica gel to remove the catalyst. The column was eluted with 1:1 mixture of diethyl ether: hexanes $(10 \mathrm{~mL})$. The solvents were removed in vacuo to obtain a white solid. The yield was determined by ${ }^{1} \mathrm{H}$ NMR integration, using 1,4-dimethoxybenzene as an internal standard, to be $15 \%$.

Attempt at epoxidation using 4-trifluoromethyl-2-(tert-butylsulfonyl)iodylbenzene. To a suspension of styrene (0.32 mL, $2.8 \mathrm{mmol})$ and (1R, 2R)-(-)-[1, 2-Cyclohexanediamino-N, N'bis(3, 5-di-t-butylsalicylidene)]manganese(III) chloride (8.9 mg, $14 \mu \mathrm{mol}$ ) in $\mathrm{CH}_{2} \mathrm{Cl}_{2}$ (5 mL) was added the iodylarene $9(0.11 \mathrm{~g}, 0.25 \mathrm{mmol})$, and the resulting dark brown suspension stirred at room temperature for $3 \mathrm{~h}$. Unreacted iodylarene was isolated from the reaction mixture along with a small amount of iodoarene 7a (10\%). No evidence was obtained for styrene epoxide.

\section{Acknowledgements}

We thank the CWRU Department of Chemistry and the donors of The Petroleum Research Fund, administered by the ACS, for support of this work.

\section{References}

1. (a) Varvoglis, A. Hypervalent Iodine in Organic Synthesis; Academic Press: London, 1997.

(b) Varvoglis, A. The Organic Chemistry of Polycoordinated Iodine; VCH Publishers, Inc.: New York, 1992. (c) Varvoglis, A.; Spyroudis, S. Synlett 1998, 221. (d) Varvoglis, A Tetrahedron 1997, 53, 1179. (e) Varvoglis, A. Chim. Chron. 1995, 24, 3. (f) Wirth, T.; Hirt, 
U. H. Synthesis 1999, 8, 1271. (g) Zhdankin, V. V.; Stang, P. J. Chem. Rev. 1996, 96, 1123.

2. (a) Johnson, R. A.; Sharpless, K. B. Catalytic Asymmetric Synthesis, $2^{\text {nd }}$ Edn; Ojima, I., Ed.; Wiley-VCH: New York, 2000. (b) Zhdankin, V. V.; Stang, P. J. Chem. Rev. 2002, 102, 2523.

3. (a) Carmalt, C. J.; Crossley, J. G.; Knight, J. G.; Lightfoot, P.; Martin, A.; Muldowney, M. P.; Norman, N. C.; Orpen, A. G. J. Chem. Soc. Chem. Commun. 1994, 2367. (b) ) Boucher, M.; Macikenas, D.; Ren, T.; Protasiewicz, J. D. J. Am. Chem. Soc. 1997, 9366. (c) Protasiewicz, J. D. Acta. Cryst. C. 1996, 1570.

4. Macikenas, D.; Meprathu, B. V.; Protasiewicz, J. D. Tet. Lett. 1998, 39, 191.

5. (a) Zhdankin, V. V.; Koposov, A. E.; Smart, J. T.; Tykwinski, R. R.; McDonald, R.; Morales-Izquierdo, A. J. Am. Chem. Soc. 2001, 123, 4065. (b) Hirt, U. H.; Springler, B.; Wirth, T. J. Org. Chem. 1998, 63, 7674. (c) Wirth, T.; Hirt, U. H. Tetrahedron Asymmetry 1997, 8, 32.

6. (a) Macikenas, D.; Skrzypczak-Jankun, E.; Protasiewicz. J. D. J. Am. Chem. Soc. 1999, 121, 7164. (b) Macikenas, D.; Skrzypczak-Jankun, E.; Protasiewicz, J. D. Angew. Chem. Int. Ed. 2000, 39, 2007.

7. Hadjiarapoglou, L.; Spyroudis, S.; Varvoglis, A. J. Am. Chem. Soc. 1985, 107, 7178.

8. (a) Nappa, M. J.; Tolman, C. A. Inorg. Chem. 1985, 24, 4711. (b) Bressan, M.; Morvillo, A. Inorg. Chem. 1989, 28, 950.

9. Zorn, H.; Reisinger, K. Allg. Prakt. Chem. 1966, 17, 160.

10. Zhdankin, V. V.; Kuehl, C. J.; Simonsen, A. J. Main Group Chemistry 1996, 1(3), 349.

11. Ipatieff, V. N.; Pines, H.; Friedman, B. S. J. Am. Chem. Soc. 1938, 60, 2732.

12. Iwao, M.; Iihama, T.; Mahanablis, K. K.; Perrier, H.; Snieckus, V. J. Org. Chem. 1989, 54, 26. 